NBER WORKING PAPER SERIES

\title{
MONETARY POLICY EFFECTIVENESS IN CHINA: EVIDENCE FROM A FAVAR MODEL
}

\author{
John Fernald \\ Mark M. Spiegel \\ Eric T. Swanson \\ Working Paper 20518 \\ http://www.nber.org/papers/w20518 \\ NATIONAL BUREAU OF ECONOMIC RESEARCH \\ 1050 Massachusetts Avenue \\ Cambridge, MA 02138 \\ September 2014
}

We thank Eric Hsu and Kuni Natsuki for excellent research assistance, and Yin Wong Cheung, $\mathrm{Xu}$ Han, Ryuzo Miyao, Yosuke Takeda, and seminar participants at the Chinese University, Hong Kong and NBER East Asian Seminar on Economics for helpful discussions, comments, and suggestions. The research in this paper was conducted while the authors were employees of the Federal Reserve Bank of San Francisco. The views expressed in this paper are those of the authors, and do not necessarily reflect those of anyone else affiliated with the Federal Reserve System or the National Bureau of Economic Research.

NBER working papers are circulated for discussion and comment purposes. They have not been peerreviewed or been subject to the review by the NBER Board of Directors that accompanies official NBER publications.

(C) 2014 by John Fernald, Mark M. Spiegel, and Eric T. Swanson. All rights reserved. Short sections of text, not to exceed two paragraphs, may be quoted without explicit permission provided that full credit, including $\odot$ notice, is given to the source. 
Monetary Policy Effectiveness in China: Evidence from a FAVAR Model

John Fernald, Mark M. Spiegel, and Eric T. Swanson

NBER Working Paper No. 20518

September 2014

JEL No. C38,E43,E52

\begin{abstract}
We use a broad set of Chinese economic indicators and a dynamic factor model framework to estimate Chinese economic activity and inflation as latent variables. We incorporate these latent variables into a factor-augmented vector autoregression (FAVAR) to estimate the effects of Chinese monetary policy on the Chinese economy. A FAVAR approach is particularly well-suited to this analysis due to concerns about Chinese data quality, a lack of a long history for many series, and the rapid institutional and structural changes that China has undergone. We find that increases in bank reserve requirements reduce economic activity and inflation, consistent with previous studies. In contrast to much of the literature, however, we find that central-bank-determined changes in Chinese interest rates also have substantial impacts on economic activity and inflation, while other measures of changes in credit conditions, such as shocks to M2 or lending levels, do not once other policy variables are taken into account. Overall, our results indicate that the monetary policy transmission channels in China have moved closer to those of Western market economies.
\end{abstract}

John Fernald

Research Department, Mail Stop 1130

Federal Reserve Bank of San Francisco

101 Market St

San Francisco, CA 94105

john.fernald@sf.frb.org

Mark M. Spiegel

Federal Reserve Bank of San Francisco

101 Market Street

San Francisco, CA 94105

mark.spiegel@sf.frb.org
Eric T. Swanson

Department of Economics

University of California at Irvine

3151 Social Science Plaza

Irvine, CA 92697-5100

and NBER

eric.swanson@uci.edu 


\section{Introduction}

China's economy has experienced remarkable structural and institutional change in recent decades. This change may affect the efficacy of counter-cyclical monetary and fiscal policy for Chinese economic activity and inflation. In this paper, we examine whether or not that is the case in the context of a factor-augmented vector autoregression, or FAVAR, along the lines of Bernanke and Boivin (2003) and Bernanke, Boivin, and Eliasz (2005). Most previous studies have found that market-based monetary policies, such as interest rates and reserve requirements, are unimportant in China relative to more direct, blunt credit policies such as "window guidance" for commercial bank lending levels. In contrast to this literature, we find, using recent data, that interest rates and reserve requirements are more important than direct quantity measures of lending (which, on their own, are insignificant). These results suggest that ongoing institutional changes in China may have led the monetary policy transmission mechanism in that country to have become more similar to that in the U.S. and other Western market economies (see, e.g., Bernanke and Blinder, 1992, and Christiano, Eichenbaum, and Evans, 1999).

Studying the monetary transmission mechanism in China raises two interesting challenges that motivate our approach of using a FAVAR model on relatively recent data. First, the well-known skepticism about the quality of Chinese data-which even Vice Premier Li Keqiang famously admitted were unreliable 1 - makes a FAVAR very appropriate. That is, we take a broad and expansive approach and use a large number of series associated with Chinese economic activity and inflation to estimate the true underlying, latent values of these series. Second, the rapid pace of institutional and structural change in China motivates our focus on the

\footnotetext{
${ }^{1}$ Wikileaks (2007).
} 
recent period, which includes both the Great Recession and the ensuing recovery. To the extent that China's economy, as well as its policy and banking institutions, have become more marketoriented, it is reasonable to think that the monetary transmission mechanism might have evolved as well.

In terms of Chinese data, the quality of the reported output figures has long been under scrutiny (e.g., Holz, 2003, 2008; Nakamura et al., 2014). One approach, which we follow in our FAVAR model, is to focus on a variety of measures of economic activity. For example, Vice Premier Li claimed that he looked at several indicators such as electricity production, rail cargo shipments, and loan disbursements to gauge Chinese economic activity. In a recent study, Fernald and Spiegel (2013) validate the information content of a range of indicators of Chinese economic activity relative to an external, independent statistical measure of that activitynamely, exports to China and Hong Kong, as reported by their major trading partners (the United States, European Union, and Japan). This measure should be highly correlated with true economic activity (either through domestic absorption or through re-processing for export), but is not subject to manipulation or bias by Chinese officials. Fernald and Spiegel report that a number of the alternative indicators they examine are more informative than is GDP as measures of economic activity. Moreover, they find that these alternative indicators typically do better in combination-i.e., taking the first principal component of a set of indicators. They find that a small set of indicators are particularly informative (electricity usage, new floor space added, China's reported exports, and raw materials used), but the more general point is the informational content of the economic indicators other than GDP.

A FAVAR approach is particularly well suited to examine monetary policy effectiveness when output and inflation are imperfectly observed, latent variables. Under this approach, one 
considers a large number of economic indicators to estimate the unobserved latent variables that drive the systematic components of the economy. This approach also minimizes ad hoc decisions about which data to include in a VAR and which not. Indeed, even in the U.S. context with relatively reliable data, Bernanke and Boivin (2003) and Bernanke et al. (2005) note that series such as output and inflation are not directly observable - there are a variety of measures of each. They argue that the FAVAR approach leads to better empirical estimates.

Applied to China, the dynamic factor model approach distills a diverse set of economic indicators into underlying factors representing Chinese economic activity and inflation. The factor-model logic suggests that such activity and inflation factors are plausibly more accurate measures of these variables than any individual data series, and therefore may better represent the information sets relevant for policymakers or used by economic agents to make decisions.

Turning to the monetary transmission mechanism, market-based monetary policy instruments (such as changes in interest rates) were generally considered inadequate to control China's economy in the 1990s. For example, Qin et al. (2005) argue that this inadequacy reflected the slower pace of reforms in the banking and financial sectors relative to the rest of the economy. As a result, studies of this period suggest that interest-rate policies pursued by the Peoples' Bank of China (PBOC) had little, if any, impact on the real side of the Chinese economy (e.g., Geiger, 2006; Laurens and Maino, 2007). Instead, policymakers seeking to control cyclical fluctuations relied on relatively direct credit policies, such as telling banks when to lend and not to lend. Studies of monetary policies pursued by the PBOC during this period tend to find that the monetary authority pursued a simple money growth rule, as in the case of Burdekin and Siklos' (2008) findings for their 1990-2003 sample period. 
As the 1990s came to a close, financial liberalization in China appeared to increase the impact of monetary policy — and interest-rate policies in particular—on the real side of the Chinese economy (e.g., Dickinson and Liu, 2007). Zhang (2009) demonstrates in a DSGE model of the modern Chinese economy that an interest rate targeting rule employed by the PBOC would likely be more effective than a money supply targeting rule in stabilizing China's economy. Chen et al. (2011) argue that the effectiveness of non-standard forms of monetary policy, such as "window guidance" for commercial bank lending levels, are likely to diminish as financial markets become less distorted. Similarly, Fukumoto et al. (2010) argue that Chinese window guidance has been successful in the past, but that its success will diminish as the Chinese financial sector develops, in favor of more standard instruments, such as policy interest rates. Still, financial liberalization is incomplete in China, with remaining ceilings on bank deposit rates and floors on lending rates (e.g. Feyzioğlu et al., 2009).

Given this institutional environment, it is an open question how standard China's monetary transmission mechanism currently is, where the standard monetary transmission channel would be exemplified by the findings in Bernanke and Blinder (1992) and Christiano et al. (1999). ${ }^{2}$ To investigate this issue, we incorporate our dynamic factor model estimates of Chinese output and inflation into a standard monetary policy VAR, identified via a recursive ordering as in the studies above.

\footnotetext{
${ }^{2}$ It is beyond the scope of this paper to analyze the full range of policy tools. Today, Chinese monetary policy employs multiple instruments and targets (He and Wang, 2012), and the relative importance of these instruments is unclear. He and Wang (2012) characterize China's monetary policy framework as a "dual rate system," where deposit and lending rates, as well as window guidance targets for lending are set by monetary authorities, while bond rates are market-determined. They argue that this framework is conducive to continued liberalization of Chinese financial markets. We also do not discuss optimal policy. Liu and Zhang (2010) demonstrate in a particular model for China that a hybrid monetary policy that targets both the money supply and the interest rate would outperform one that targets the interest rate alone.
} 
We begin with a simple three-equation FAVAR, comprising an economic activity factor, an inflation factor, and a (single) monetary policy instrument. In contrast to the previous literature, we find that increases in PBOC benchmark interest rates have standard impulse responses - that is, economic activity slows significantly in response to the shock, and inflation falls. Increases in reserve requirements also slow economic activity significantly. In contrast, innovations to M2 or lending have modest—and statistically insignificant—effects on output and inflation. ${ }^{3}$

These findings are representative of those from larger FAVAR systems as well: Innovations to interest rates and reserve requirements have economically and statistically significant effects, while our large standard error estimates for innovations to lending, M2, and government spending are consistent with no impact.

Of course, lending could still be part of the monetary transmission mechanism, as it is in standard market-oriented economies such as the U.S. That is, increases in interest rates and (to a lesser extent) reserve requirements do reduce the pace of growth of lending and monetary aggregates. The lack of an independent effect of innovations in these aggregates to these variables is consistent with typical findings for the U.S., where much of the variation in quantity aggregates reflects idiosyncratic shocks to money demand rather than systematic policy (e.g., Bernanke and Blinder, 1992).

Our FAVAR allows us to analyze the role of countercyclical policy during and since the recent global financial crisis. China's growth experience during this period was exceptional:

\footnotetext{
${ }^{3}$ We also consider the effects of a fiscal policy instrument—overall government spending — because, to the extent that Chinese policymakers use multiple levers simultaneously, changes in monetary instruments could have a fiscal component as well. However, we find that the standard error bands for the effects of government spending are very large, due the very high month-to-month volatility of that variable.
} 
while economic activity in both advanced and emerging economies fell dramatically, China's real GDP growth remained robust, averaging 7.4 percent during the period covering the U.S. recession. (This performance is all the more remarkable given that China's heavy reliance on trade might have been expected to make it exceptionally vulnerable to the global downturn.) Surprisingly, we find that China's strong performance during the global financial crisis was not attributable to countercyclical monetary policy pursued by the Chinese government. That is, in the context of our FAVAR, when we set the interest-rate and reserve-ratio innovations to zero, China's economic performance during the crisis would actually have been better. The reason is timing: China was tightening monetary policy early in 2008. Given the estimated transmission lags, the contractionary effects of that tightening were hitting the economy in late 2008 and into 2009 - exacerbating the effects of the global financial crisis on China.

The paper most closely related to the present one is He, Leung, and Chong (2013), who also use a FAVAR model to estimate the effects of Chinese monetary policy on the Chinese economy. ${ }^{4}$ In contrast to the present paper, those authors treat Chinese output and inflation as observed variables (measured by industrial production and the consumer price index, respectively), and use latent factors to capture the effects of other variables on the Chinese economy, such as other Chinese economic indicators and measures of U.S. output and inflation. They find that industrial production responds modestly to a shock to either the benchmark lending rate or "market-based" $\mathrm{PBOC}$ policies, but responds strongly to shocks to total lending or M2. In contrast, we apply a dynamic factor model to Chinese output and inflation as well, given the widespread concerns about the quality of official Chinese measures of those variables.

\footnotetext{
${ }^{4}$ Lescaroux and Mignon, (2009) also estimate a FAVAR model for China to measure the impact of global oil shocks on the Chinese economy. They do not examine the effects of monetary policy, but do include M2 as one of their economic indicator variables.
} 
We also perform our analysis on a more recent sample then He et al. (2013), and are thus better able to study the performance of the Chinese economy during the recent global financial crisis and recovery.

The remainder of our paper is organized into 6 sections. Section 2 introduces our FAVAR methodology. Section 3 describes our data. Section 4 presents our main results. Section 5 conducts a number of robustness checks of those results. Section 6 concludes. An Appendix provides additional robustness analysis.

\section{FAVAR Estimation Method}

Economic agents in China and elsewhere look at a wide variety of economic indicators to synthesize a view of the state of the economy. However, estimating a standard vector autoregression (VAR) for a large system of variables is infeasible without a very long history of data. This is particularly problematic for China, due to its combination of limited data availability and rapid structural transformation. In practice, then, the relatively short samples of consistent data that we have for Chinese series makes estimation of large VARs either impossible or highly unreliable due to overparameterization.

In a dynamic factor model, however, a small number of essential factors are extracted from the set of all observable data — for example, a Chinese "economic activity" factor can be extracted from data series on industrial production, electricity use, rail cargo shipments, loan disbursements, international trade data, and so on. By focusing attention on the essential underlying factor (economic activity), the dimensionality of the model can be greatly reduced, allowing for estimation of a VAR in the underlying factor. 
In particular, we assume that our numerous Chinese economic indicators, $X_{t}$, are determined by only a small number of underlying factors, $F_{t}$, plus idiosyncratic noise, $\varepsilon_{t}$, according to:

$$
X_{t}=\Lambda F_{t}+\varepsilon_{t}
$$

where $t$ indexes observations, the size of the vector $F_{t}$ is less than the size of the vector $X_{t}$, and the matrix $\Lambda$ is called the loadings of the indicators $X$ on the factors $F$. The idiosyncratic errors $\varepsilon_{t}$ may be correlated both across series and across observations $t$, so long as that correlation is not "too strong." 5

In a dynamic factor model, the factors $F$ (and data series $X$ ) are related over time, typically according to a linear process:

$$
F_{t}=A(L) F_{t-1}+\eta_{t}
$$

where $A(L)$ denotes a polynomial in the lag operator. Dynamic factor models date back to papers by Geweke (1977) and Sims and Sargent (1977). They have enjoyed a great resurgence of interest since Stock and Watson (1998, 1999), and Forni et al. (2000), building on previous work by Connor and Korajczyk (1986), showed how these models can be efficiently applied to large panels of macroeconomic time series.

\footnotetext{
${ }^{5}$ For details, see Chamberlain and Rothschild (1983) and Stock and Watson (2000). In the classical literature on factor analysis, the idiosyncratic errors $\varepsilon$ are assumed to be uncorrelated across series and over time. This led Chamberlain and Rothschild (1983) to coin the term "approximate factor model" to refer to the more general case considered here. Consistent with the modern literature, we use the term "factor model" to refer to the more general case.
} 
A factor-augmented VAR, or FAVAR, is a VAR in which some of the variables are factors taken from a dynamic factor model:

$$
\left[\begin{array}{l}
F_{t} \\
Y_{t}
\end{array}\right]=A(L)\left[\begin{array}{l}
F_{t-1} \\
Y_{t-1}
\end{array}\right]+\eta_{t}
$$

where $Y_{t}$ denotes a vector of observable variables and $F_{t}$ a vector of factors as above. Thus, a

FAVAR differs from a dynamic factor model in two main respects: First, some of the factors are assumed to be directly observed, while in a dynamic factor model this is generally not the case. ${ }^{6}$ Second, in a FAVAR, the econometrician is typically interested in identification of the FAVAR, rather than just forecasting. Thus, the key objects of interest in a FAVAR are typically impulse response functions or variance decompositions, rather than just forecasts.

Following Stock and Watson $(1998,1999)$, we use principal components to estimate the factors $F_{t}$ in the dynamic factor model (1). This method is numerically robust and computationally efficient, and is econometrically consistent for the latent factors $F$ under the standard technical conditions discussed in Stock and Watson $(1998,1999)$. In contrast to Stock and Watson, but consistent with some other studies in the literature (e.g., Ang and Piazzesi, 2003), we divide our economic indicators into two groups—one containing measures of output and the other containing measures of inflation - and extract the first principal component from

\footnotetext{
${ }^{6}$ Bernanke and Boivin's (2003) preferred specification for U.S. data is to treat the federal funds rate as the observed variable in the model, but they also consider specifications in which output and/or inflation are also observed. For China, He et al. (2013) assume that industrial production and the CPI are observable variables. Given the questions that have been raised about the quality of Chinese data, we prefer to treat IP and the CPI as noisy indicators of the underlying latent activity and inflation factors.
} 
each group to get our measures of an "output" factor and an "inflation" factor. ${ }^{7}$ This approach aids intuition by ensuring that each factor has a clear economic interpretation. ${ }^{8}$

Given that many Chinese series have short histories or periods of missing data, our treatment of missing data is of central importance. We first estimate the latent factors $F$ and factor loadings $\Lambda$ from the data $X$ using only those months for which we have data on all series, say from some date $t_{0}$ to the end of our sample $T$. We next impute values for any data that are missing in month $t_{0}-1$. We infer the values of the latent factors $F_{t_{0}-1}$ using the data that are observed in month $t_{0}-1$ together with the factor loadings $\Lambda$ and variances of the idiosyncratic errors $\varepsilon$ and $v$. Once we have imputed values for the missing data in month $t_{0}-1$, we reestimate the factor loadings $\Lambda$ and latent factors $F$ over the sample from $t_{0}-1$ to $T$. We iterate this process backward, month by month, until we have imputed missing values for all series in all months $t$. This is essentially the same procedure as advocated by Stock and Watson (1998) for dealing with missing data.

As we demonstrate below, our estimate of Chinese economic activity captures well the broad macroeconomic movements in China, particularly the impact of the global financial crisis and the subsequent recovery from that period. Following Bernanke and Boivin (2003) and Bernanke et al. (2005), we then incorporate our estimate of Chinese economic activity into a

\footnotetext{
${ }^{7}$ We also considered a specification with two output factors, measured as the first and second principal components of the economic activity indicators, and an inflation factor measured in the same way as above. The variance shares of the output factors were about $16 \%$ and $12 \%$, respectively. While the second factor's variance was non-trivial, the impulse response functions for the extended six-variable FAVAR were quite similar to that reported for our baseline five-variable FAVAR below. We thus use a single output factor for our baseline specification in the interest of parsimony.

${ }^{8}$ In the robustness analysis of Section 5, we consider the alternative approach of extracting two factors from all of the data collected into a single group.
} 
VAR. We can then apply standard VAR methods to estimate and identify the effects of Chinese monetary policy on the economy.

An important question is how we identify the monetary policy instrument and monetary policy shocks. For equation (3), we treat the policy variables as observables, i.e., the elements of $Y$. We then assume a typical recursive ordering, with the economic activity and inflation factors ordered first, followed by the policy variables - i.e., we assume that policy can respond endogenously to changes in activity or inflation within the month, but that policy innovations affect economic activity and inflation with a lag of one month or more.

\section{Data}

We start our sample in January 2000 and end in September 2013. Because of rapid institutional and structural change in China, data from the 1990s is arguably not very informative about the current workings of monetary policy, a view that is supported by He et al. (2013), who identify a structural break in the relationships among Chinese data in 2002. Importantly, our sample period covers the sharp downturn during the global financial crisis as well as China's rapid subsequent recovery.

Note that some of the most important series that one might want to include in a set of measures of economic activity, such as the PMI manufacturing index, are only available for China beginning relatively recently, in 2005. This highlights the usefulness of our FAVAR methodology for China, which allows the inclusion of variables that have missing values over some portion of our sample. ${ }^{9}$

\footnotetext{
${ }^{9}$ Although our FAVAR model is designed to fill in missing variables, the lack of continuity in the data is also a reason for focusing on the more recent period rather than extending back to the 1990s. In particular, if most of the variables are missing, it is unclear how comparable the estimated factors are over time.
} 
The Chinese New Year raises a particular challenge. This holiday has a major effect on monthly economic activity, but sometimes falls in January, sometimes in February, and sometimes crosses both months. We address this issue for each individual economic activity and inflation variable $x_{i t}$ by first averaging the values of the series for January and February. We then distribute that average value across the two months assuming that the growth rate from December to January equals the growth rate from January to February. This assumption addresses the large swings in economic activity that appear in our data for these two months, but also implies that we are not getting any identification from those two months considered separately.

After removing the effects of the Chinese New Year, we use the Census X-12 ARIMA package to seasonally adjust the raw levels of each individual variable. ${ }^{10}$ We then take monthto-month growth rates (calculated as 100 times the log-change) of each series and, following Stock and Watson (2012), remove a local mean from each series via a biweight filter. We then apply the factor-model methodology as described above to the seasonally-adjusted monthly growth rates in order to extract the activity and price factors.

A list of all the variables included in our study is provided in Table 1 (all variables were downloaded from the CEIC Asia Database). As in Ang and Piazzesi (2003), we divide the data series into two categories, economic activity and inflation, on a priori grounds. For economic activity, our baseline specification includes a broad set of 29 different indicators that we expect to be correlated with Chinese output. As a robustness check, we also consider a "narrow" set of indicators for economic activity based on the work of Fernald and Spiegel (2013). Those authors

\footnotetext{
${ }^{10}$ In principle, the X-12 package can be used to adjust for moving holidays or other calendar effects such as Chinese New Year. However, those adjustments require imposing a fair degree of judgment about the impact of these calendar effects that is beyond the scope of this paper.
} 
validate potential indicators of Chinese economic activity against an independent statistical measure of that activity, namely, exports to China and Hong Kong as reported by their major trading partners (namely, the United States, European Union, and Japan). Fernald and Spiegel argue for taking the first principal component of electricity usage, new floor space added, China's reported exports, and raw materials used. We use this narrower set of indicators (excluding raw materials, which is only available quarterly) as a check on the results of our more comprehensive factor model using all 29 economic activity indicators. ${ }^{11}$

For inflation, we have a smaller set of available economic indicators, comprising four measures of consumer prices and two of producer prices.

The top panel of Figure 1 presents estimates of the latent Chinese economic activity factor generated by the broad and narrow data sets, along with Chinese industrial production (IP) for comparison. In the figure, it can be seen that the estimates of economic activity are highly correlated, both with each other and with the IP series. This is fairly reassuring, since these series are intended to capture essentially the same latent variable. The narrow economic activity factor appears to have more high-frequency noise and volatility than the broad factor, and IP seems to be somewhat noisier and more volatile than both of the latent factors, consistent with the view that adding more indicators improves our estimate of the true underlying state of economic activity in China. Our economic activity estimates also capture well the slowdown in China during the global financial crisis, and the country's subsequent recovery. It is apparent that while China weathered the economic downturn better than most, it also was heavily hit by

\footnotetext{
${ }^{11}$ Boivin and $\mathrm{Ng}$ (2006) demonstrate that adding more data to a dynamic factor model can, in principle, have the perverse effect of reducing forecast quality if the idiosyncratic errors of the factors are highly cross-correlated or if a factor with substantial forecasting power is dominant in a small dataset but is a dominated factor in a larger dataset. By considering a "narrow" as well as "broad" data set for our dynamic factor model, we make our analysis more robust to this potential problem.
} 
the global downturn. Finally, Figure 1A suggests that our methodology for filling in missing data does not distort our estimate of economic activity, since our narrow factor is based on indicators for which we have a complete history of data over our sample. ${ }^{12}$

The bottom panel of Figure 1 reports our estimated inflation factor. Again, our series appears to be picking up the effects of the crisis well, including both the downturn in prices during the crisis and the subsequent pickup in Chinese inflation during the recovery. As in the case of the economic activity series, the data clearly demonstrate a strong impact from the crisis on Chinese prices.

For monetary policy, we consider five observable measures, reported at the bottom of Table 1: a benchmark short-term (less than 20-day) interest rate set by the PBOC; a longer-term rate (6 months or less) for loans from the PBOC; the reserve requirement ratio; the money supply, as measured by M2; and the quantity of bank lending. The bank lending variable should, in principle, capture changes in window guidance, the Chinese government's well-documented policy of manipulating credit conditions through direct instructions to banks concerning whether to increase or decrease their lending activity. ${ }^{13}$ Interest rates and reserve requirements are in units of percentage points, and we do not seasonally adjust them. M2 and bank lending are in units of seasonally-adjusted month-to-month growth rates. ${ }^{14}$ As with the individual data series,

\footnotetext{
${ }^{12} \mathrm{We}$ also experimented with estimating an economic factor directly on 12-month changes in the data, rather than on month-to-month changes. The correlation of the resulting narrow and broad factors was 0.88 . Clearly, there is much more noise in the month-to-month estimates, especially with the narrow measures. That said, the year-overyear indicators would not be appropriate given the "ordering" identification in our VAR.

${ }^{13}$ While we do not explicitly account for sterilization activity, our measure of M2 should also reflect central bank sterilization decisions through the central bank's budget constraint, as in Chang et al. (2012).

${ }^{14} \mathrm{We}$ do not account for some of the policies that have been pursued by Chinese authorities. For example, the PBOC on several occasions took regulatory steps which appeared to curb activity in the "shadow" banking system of China. It would be difficult for us to characterize the magnitudes of these policy actions. Of course, if these actions are correlated with other, observed, policy moves, the VAR may pick them up.
} 
we remove a local mean from each of these policy variables (other than the interest rates, although that didn't matter) using a biweight filter. ${ }^{15}$

Finally, we also consider a measure of fiscal policy - the seasonally-adjusted month-tomonth growth rate of government spending, which includes both central and local government spending - because, to the extent that Chinese policymakers use multiple levers simultaneously, changes in monetary instruments could have a fiscal component as well. ${ }^{16}$

\section{Results}

We begin by considering simple three-variable VAR systems, with the economic activity factor, inflation factor, and each policy variable individually. All of our main empirical results come through in this simple specification. We then consider the policy variables in combination, but our main conclusions that policy interest rates and reserve requirements matter-while M2 and lending have modest or no effects — remain robust. In all cases, we estimate our model with two monthly lags for each of the variables, in accordance with the AIC and BIC lag-selection criteria. $^{17}$

Figure 2 reports results using the broad economic activity factor. Each row of Figure 2 corresponds to a different three-variable VAR, including a different monetary policy instrument. Each row of the figure graphs the impulse responses of the economic activity and inflation

\footnotetext{
${ }^{15}$ Results were not much affected by the filtering. The exception was for the reserve requirement, where the raw data show a marked rise starting in 2007, with a modest dip down decline during the financial crisis, and then a further rise. Without filtering, this trend shows up as an effect that is larger and a priori too persistent, relative to what we report. This example highlights some of the caveats around any VAR using a short sample of data.

${ }^{16} \mathrm{We}$ also considered the overall fiscal surplus as a measure of fiscal policy. This variable was also insignificant in its impact on our activity series. However, we prefer the government spending variable as it appears to be much less noisy from month to month.

${ }^{17}$ Depending on the model, the criteria typically choose between one and three lags. Results are robust to allowing for three lags. Allowing more lags inherently leads to choppier and less precise results, given the relatively short sample we use and the explosion in the number of parameters. He et al. (2013) also use two lags.
} 
factors to a one-standard-deviation shock to the corresponding monetary policy instrument, assuming a recursive ordering for the variables in which the monetary policy instrument is positioned last (so that monetary policy can respond within the month to output and inflation, but neither output nor inflation responds within the month to monetary policy). We concentrate on the responses of the factors themselves, rather than the observable economic indicators, as those may be subject to misreporting or bad measurement (e.g., Fernald et al., 2013). In all cases, we plot cumulated impulse responses (with one-standard-deviation standard error bands); since the activity and inflation factors correspond to growth rates rather than levels, the cumulated responses tell us how the levels of activity and prices respond to a given policy innovation.

The top row shows our main result: In response to a positive shock to the PBOC shortterm interest rate, both activity and (with a lag) prices fall significantly over the next two years. These responses are in line with standard intuition and results for the effects of monetary policy in market-oriented economies such as the U.S. (e.g., Christiano, Eichenbaum, and Evans, 1999). In contrast, most studies of China do not find that market-based policy instruments are statistically significant (e.g., He et al., 2013). We explore the robustness of this result further below. ${ }^{18}$

The second row of Figure 2 shows that an increase in the required reserve ratio also reduces economic activity and prices significantly.

Interestingly, rows three and four show that innovation to monetary aggregates (M2) and bank lending have a positive effect on economic activity and prices, as one would expect, but these responses are not statistically significant, differing from zero by only about one standard

\footnotetext{
${ }^{18} \mathrm{We}$ also looked at the response to innovations in the PBOC rate for loans up to six months as the monetary policy instrument and obtained results that were qualitatively similar.
} 
error. Our FAVAR model thus suggests that movements in monetary aggregates and window guidance in the form of quantitative targets for lending may not, in fact, be important channels for monetary policy over this period. Indeed, the lack of a substantive effect of innovations in M2 or bank lending on activity and inflation is consistent with typical findings for the U.S., where much of the variation in quantity aggregates reflects idiosyncratic shocks to money demand rather than fundamental changes in monetary policy (e.g., Bernanke and Blinder, 1992).

These simple results contrast with those of He et al. (2013), who find that economic activity is substantively positively affected by increases in credit availability, as measured by the volume of bank lending. Those authors also do not find a role for PBOC interest rates. ${ }^{19}$ We discuss some reasons for the differences between their results and ours below.

Finally, the bottom row of Figure 2 shows that government expenditures also have a small but insignificant positive effect on economic activity and prices. We note, however, that the monthly government spending data appears to be very noisy and may not be a good measure of the true stance of fiscal policy. As such, we view the inclusion of government expenditures in our specification as primarily a vehicle to enhance our ability to gauge the impact of different monetary policy instruments by allowing for fiscal effects. ${ }^{20}$

Figure 3 reports analogous results using the narrow economic activity factor rather than the one estimated using the broader set of indicators. Results for interest rates are qualitatively similar, though less statistically significant, which we attribute to the fact that the narrow

\footnotetext{
${ }^{19} \mathrm{Ju}$ et al. (2013) also find a role for monetary policy to influence Chinese trade activity through its influence on the credit channel in a micro study.

${ }^{20} \mathrm{We}$ also examined government spending shocks in a five-variable specification with reserve requirements and the benchmark interest rate added. Fiscal policy consistently failed to have a significant impact on the economic activity or price factors, regardless of the ordering of the fiscal policy shock within the system.
} 
economic activity factor seems to be less precisely estimated than the broad factor, owing to the smaller number of indicators used. In particular, the policy innovations that displayed tenuous significance using the broad activity factor-M2, bank lending and government spending — are now often inside the one-standard-error bands. Among these, only bank lending retains even its marginally significant positive impact on economic activity, while none of the three have a noticeable (or statistically significant) impact on prices. Nevertheless, it is reassuring that a much noisier, but externally verifiable, measure of economic activity yields qualitatively similar results for the policy variables that seem to matter the most, namely interest rates and reserve requirements.

Figures 4 and 5 report results for larger, five-variable FAVAR systems. In terms of recursive ordering, both systems include the broad economic activity factor and inflation factor as the first two variables, and the required reserve ratio and short-term interest rate as the last two variables. $^{21}$ The third variable in each of the figures differs-Figure 4 uses M2, and Figure 5 the quantity of bank lending. The ordering assumptions imply that the reserve ratio or the short-term interest rate can respond within the month to changes in M2, or bank lending, or government spending, but that those variables do not respond within the month to the reserve ratio or the overnight interest rate. ${ }^{22}$ (That said, putting M2 or lending last in the VAR doesn't affect our results much.)

\footnotetext{
${ }^{21} \mathrm{We}$ focus on the short-term interest rate because it was so similar to results with the six-month rate.

${ }^{22} \mathrm{We}$ do not have a strong view as to whether output or inflation should be ordered before the other in the VAR (and, in fact, both recursive orderings are suspect). For the impulse responses we are interested in - namely, the responses to the monetary policy instruments - the relative ordering of output and inflation in the VAR does not matter, so our results are robust to this choice. However, it should be kept in mind that the impulse responses in the first two rows of Figures 4 and 5 do depend on the ordering of these two variables.
} 
The results from the simple three-variable systems are remarkably robust. Shocks to the short-term interest rate reduce economic activity and prices, and shocks to the required reserve ratio also reduce activity. But M2 remains quantitatively unimportant for activity, and both M2 and bank lending exhibit price "puzzles" (responses that seem to have the wrong sign) according to these models.

Still, the results do show that M2 and lending are not just noise. Both decline (lending significantly so) when the short-term interest rate rises. This suggests that some of the effect of the interest rate increases might be working through reduced lending (as one would expect), even if innovations to lending per se do not appear to matter. This would be in keeping with the standard monetary transmission mechanism (e.g., Bernanke and Blinder, 1992), as well as some of the findings in the literature for China (e.g., Ju et al., 2013) that suggest part of the impact of monetary policy is through its influence on lending and credit.

An interesting question is why we find different results from previous studies, such as $\mathrm{He}$ et al. (2013). Subsequent to identifying a structural break in China's monetary transmission mechanism with the launch of its floating exchange rate regime in 2005, those authors find that industrial production responds modestly to a shock to either the benchmark lending rate or to their estimate of the stance of "market-based" PBOC policies as a latent variable for their latter sample period estimated from 2002-2010. ${ }^{23}$ They generate the market-based policy measure by choosing 15 policy data series, including interest rate and reserve requirement policies as indicator variables. In contrast to the market-based policy stance, they find strong responses of industrial production and prices to shocks to total lending or M2 for this latter period, and

\footnotetext{
${ }^{23}$ Note that their time period roughly corresponds to our 2000-2013 time period, indicating that the move to a managed exchange rate peg should not pose a structural break problem for our analysis. They identify no impact for the early period, which runs from 1998-2005.
} 
conclude that controlling loan volumes or the money supply is "more effective" than manipulating market-based monetary instruments in China.

Our paper differs from He et al. (2013) in a number of respects. First, we use more recent data, with substantively more coverage of the global financial crisis and its aftermath. Second, we apply the FAVAR framework somewhat differently: while He et al. (2013) treat industrial production and the consumer price index as observed series, we put little faith in the reliability of any individual activity or price series and instead rely on the factor model to characterize Chinese economic activity and inflation; we then examine the response of these factors to observed movements in policy variables, such as the overnight lending rate or reserve requirements. Our approach is more in keeping with the standard FAVAR literature (e.g., Bernanke et al., 2005), which as discussed above is particularly suited to address the problems associated with noise in Chinese data and that country's rapid structural transformation. Third, our dynamic factor estimation methodology allows us to consider indicator variables with missing values, which enables us to include a broader set of indicators to characterize economic activity. This feature is particularly desirable for China, where many important series contain episodes of missing values or start in the middle of our sample.

We are able to partially replicate previous studies with our model, and several results are suggestive. First, if we end our sample prior to the failure of Lehman Brothers (when the Great Recession became Great), then interest rate innovations are unimportant. Thus, including the Great Recession period is important for our finding that interest rates matter. Even over the earlier sample, however, we find that M2, bank lending, and government spending remain unimportant in our VAR. Second, some previous studies do not control for Chinese New Year the way we do. For example, He et al. (2013) run X-12 on raw monthly growth rates without 
controlling for the changes in timing of the New Year from one year to the next. When we follow that approach, we find that M2 and government spending are marginally significantly expansionary. This result appears to be spurious, being completely a reflection of the systematic, contemporaneous comovement in economic activity, M2, and government spending around Chinese New Year. Hence, these results point to the importance of treating the Chinese New Year carefully - either the way we have in this study, or else modeling the time-varying monthly seasonal explicitly. Importantly, the interest-rate responses that we estimate are largely unaffected by whether we control for Chinese New Year or not, perhaps because interest rates do not show much seasonal variation around the New Year holiday. Finally, given that we find interest rates and reserve requirements have a significant effect on economic activity and inflation, an important question is how important are they for the actual observed variation in activity and prices?

We address this question in two ways. First, variance decompositions (not shown) show that innovations to interest rates and reserve requirements explain only a modest share of the variation in economic activity and prices. For example, in the five-variable VAR with M2, innovations to interest rates and reserve requirements together explain about 20 percent of the variance in activity and less than 10 percent of the variance in inflation at horizons of 12 or 24 months. Not surprisingly, in a fast-growing, rapidly evolving economy like China's, nonmonetary factors are much more important in explaining the pace and volatility of growth. Second, Figure 6 reports counterfactuals for three-variable VAR specifications in which we include the economic activity factor, inflation factor, and either the benchmark interest rate (Figure 6A) or reserve requirements (Figure 6B). We examine the counterfactual of how the economic activity factor would have evolved if we "turned off" the innovations to the short-term 
interest rate and reserve requirements, respectively. These results show that, during the Great Recession, monetary policy actually exacerbated the slump in economic activity to some extent. The reason is intuitive: China tightened monetary policy in early 2008 . The contractionary effects of those policy moves were hitting the economy later in 2008 - when the global economy, and China's economy with it, were hit by the downturn. This experience illustrates one of the challenges of countercyclical monetary policy.

\section{Robustness}

\subsection{External shocks}

As China is a very open economy with a heavy reliance on imported raw materials, external shocks are potentially very important. As a robustness check on our above results, we therefore add a monthly proxy for external output (namely, U.S. industrial production) and an index of commodity prices. This results in a seven-variable specification, with produces the impulse response functions shown in Figure $7 .^{24}$

Our earlier results for the five-variable system are largely robust to the inclusion of these additional external variables. In particular, we continue to find that an increase in the benchmark interest rate results in a persistent decline in both economic activity and inflation. We also continue to find that an increase in the required reserve ratio results in a persistent decline in economic activity and inflation, the latter with a lag. We also continue to not find a significant role for money supply (M2) shocks.

\footnotetext{
${ }^{24}$ To treat the external shocks as contemporaneously exogenous, we order our seven-variable specification with the U.S. industrial production variable first, the commodity shock series second, and series three through seven following the same order as the five-variable series reported in Figure 4, above.
} 
In terms of the effects of external shocks on the Chinese economy, we largely obtain expected results as well. A positive shock to U.S. industrial production results in a persistent increase in both economic activity and Chinese inflation, again, the latter with a lag. We do get a positive short-term relationship between positive commodity price shocks and economic activity, but that is likely spurious as we also find a positive relationship between U.S. industrial production and commodity prices. U.S. industrial production is likely to be a noisy indicator for overall global activity outside China, which may push up both commodity prices and Chinese economic activity. We do find that a positive commodity price shock pushes up Chinese inflation initially, as would be expected.

\subsection{Pooled factor data}

Our specifications follow Ang and Piazzesi (2003) and others in categorizing indicator variables as being associated with either economic activity or inflation. An alternative approach, followed by Bernanke et al. (2003), is to pool all of the observable indicator variables and estimate the latent factors of the model directly on this single set of indicators.

An advantage of this latter method for the present paper is that our inflation factor is based on a relatively small number of Chinese inflation indicators that are available at a monthly frequency for a sufficiently long time period. The six inflation indicators that we do use could be insufficient for obtaining good estimates of true Chinese inflation (but would nevertheless be better than using any single indicator such as the CPI!). As a robustness check, we thus reestimate our baseline specification using all 34 of indicator variables to estimate two latent factors without any category restrictions. As shown in Figure 8a, the first estimated factor from this procedure matches the economic activity factor from our baseline specification extremely closely. Similarly, Figure $8 \mathrm{~b}$ shows that the second fitted factor also matches the inflation factor 
from our baseline specification very closely. The correlation coefficient between the first factor and the activity factor estimated above was 0.89 , while the correlation coefficient between the second factor and the above price factor was 0.29. Nevertheless, as shown in Appendix Figure A1, the impulse response functions with these factors substituted for the activity and price factors in the five-variable specification in Figure 4 look quite similar to those in that figure. In particular, we continue to find that a positive shock to the domestic interest rate has a persistent negative impact on the first factor and also on the second factor, the latter with a lag.

\section{Conclusions}

This paper uses a FAVAR methodology to assess the impact of Chinese monetary policy. A FAVAR approach appears to be particularly well suited to the Chinese economy, both due to its relatively short span of quality data available and to the likely fact that Chinese economic conditions and policy rules have changed dramatically over recent years. Our FAVAR approach accommodates data with different starting dates, and therefore allows for a broad set of indicator variables. Moreover, the FAVAR representation allows for the incorporation of many activity and price indicator variables while retaining a parsimonious VAR specification to assess policy impacts. Again, this is particularly promising for China, as the time series available for analysis are relatively short while the data are likely to be noisy and therefore benefit from our broad set of indicator variables.

Our results suggest that, contrary to earlier findings in the literature, China's monetary transmission mechanism is beginning to look more standard. In particular, we identify a substantive role for interest rate policies in the determination of both real economic activity and prices. The latter occurs with a lag. While these results contrast with earlier studies of the Chinese economy, they are directly consistent with a number of studies in the literature for the 
U.S., suggesting that China's idiosyncratic monetary transmission mechanisms may be a function of distortions to the Chinese economy, particularly in the Chinese commercial banking system. These studies predict that, as these distortions diminish, the standard monetary policy instruments are likely to gain importance in the monetary transmission mechanism and consequently, in Chinese monetary policy.

An important caveat is that our monetary policy FAVAR analysis does not tell us whether the channels of the monetary transmission mechanism are the same in China as in Western economies. The VAR itself simply tells us about timing. That is, the VAR finds that changes in interest rates that cannot be predicted based on current as well as lagged activity and inflation are associated with later contractions in activity and prices. The mechanisms at work in Western economies are that changes in central bank policy rates lead to changes in other market interest rates as well as broader financial conditions. These changes, in turn, affect the economic decisions of various agents in the economy. Further research is needed to assess the degree to which these channels of monetary transmission are the same in China.

Of course, China's economy is far from fully liberalized, and more non-standard Chinese monetary policies — such as window guidance to Chinese commercial banks - are likely to continue to play a role in its monetary policy going forward. Still, our results indicate that the liberalization of China's economy to date, particularly in its financial sector, has left that country's monetary transmission mechanism closer to those of Western economies than previously realized. 


\section{References}

Ang, Andrew and Monika Piazzesi (2003), "A no-arbitrage vector autoregression of term structure dynamics with macroeconomic and latent variables," Journal of Monetary Economics 50(4), 745-787.

Bernanke, Ben S. and Alan S. Blinder (1992), "The Federal Funds Rate and the Channels of Monetary Transmission," American Economic Review 82(4), 901-921.

Bernanke, Ben S. and Jean Boivin (2003), "Monetary policy in a data-rich environment," Journal of Monetary Economics 50, 525-546.

Bernanke, Ben S., Jean Boivin, and Piotr Eliasz (2005), "Measuring the Effects of Monetary Policy: A Factor-Augmented Vector Autoregressive (FAVAR) Approach," Quarterly Journal of Economics 120(1), 387-422.

Boivin, Jean and Serena Ng (2006), "Are More Data Always Better for Factor Analysis?," Journal of Econometrics 132, 169-194.

Burdekin, Richard C. K. and Pierre L. Siklos (2008), "What Has Driven Chinese Monetary Policy Since 1990? Investigating the People's Bank's Policy Rule," Journal of International Money and Finance 27, 847-859.

Chamberlain, Gary and Michael Rothschild (1983), "Arbitrage, Factor Structure, and MeanVariance Analysis in Large Asset Markets," Econometrica 51, 1305-1324.

Chang, Chun, Zheng Liu, and Mark M. Spiegel (2013), "Capital Controls and Optimal Chinese Monetary Policy," Federal Reserve Bank of San Francisco Working Paper 2012-13.

Chen, Hongyi, Qianying Chen and Stefan Gerlach (2011), "The Implementation of Monetary Policy in China: the Interbank Market and Bank Lending," HKIMR Working Paper 26/2011.

Cheung, Yin-Wong, Menzie D. Chinn, and Eiji Fujii (2010), "China's Current Account and the Exchange Rate," in R. C. Feenstra and S. J. Wei, eds., China's Growing Role in World Trade, Chapter 7, NBER, University of Chicago Press, 231-271.

Connor, Gregory and Robert Korajczyk (1986), "Performance Measurement with the Arbitrage Pricing Theory: A New Framework for Analysis," Journal of Financial Econometrics 15, 373-94.

Christiano, Lawrence, Martin Eichenbaum, and Charles Evans (1999), "Monetary Policy Shocks: What Have We Learned and to What End?" in Handbook of Monetary Economics 1A, ed. by John Taylor and Michael Woodford, Elsevier, 65-148.

Dickinson, David, and Jia Liu (2007), "The real effects of monetary policy in China: An empirical analysis," China Economic Review 18, 87-111.

Fernald, John, and Mark Spiegel (2013), "Is China Fudging Its Figures? Evidence from Trading Partner Data," unpublished manuscript, Federal Reserve Bank of San Francisco.

Forni, Mario, Marc Hallin, Marco Lippi, and Lucrezia Reichlin (2000), "The Generalized Dynamic Factor Model: Identification and Estimation," Review of Economics and Statistics 82, 540-54. 
Fukumoto, Tomoyuki, Masato Higashi, Yasanuri Inamura, and Takeshi Kimura (2010), "Effectiveness of Window Guidance and Financial Environment In Light of Japan's Experience of Financial Liberalization and a Bubble Economy," Bank of Japan Review 2010-E-4.

Feyzioğlu, Tarhan, Nathan Porter, and Előd Takáts (2009), "Interest Rate Liberalization in China," IMF Working Paper WP/09/171.

Geiger, M. (2006), "Monetary Policy in China (1994-2004): Targets, Instruments and Their Effectiveness," Wurzburg Economic Papers 68.

Geweke, John (1977), "The Dynamic Factor Analysis of Economic Time Series," in Aigner, D.J. and A.S. Goldberger (eds.), Latent Variables in Socio-Economic Models (North Holland: Amsterdam) Ch. 19.

He, Dong, and Honglin Wang (2012), "Dual-Track Interest Rates and the Conduct of Monetary Policy in China," China Economic Review 23, 928-947.

He, Qing, Pak-Ho Leung, and Terence Tai-Leing Chong (2013), "Factor-Augmented VAR Analysis of the Monetary Policy in China," China Economic Review 25, 88-104.

Holz, Carsten A. (2003), “'Fast, Clear and Accurate:' How Reliable Are Chinese Output and Economic Growth Statistics?” The China Quarterly 173, March, 122-63.

Holz, Carsten A. (2008), "China's 2004 Economic Census and 2006 Benchmark Revision of GDP Statistics: More Questions than Answers?" The China Quarterly 193, March, 150163.

Ju, Jiandong, Shu Lin, and Shang-jin Wei (2013), "Monetary Policy, Credit Constraints, and Firm Exports: Evidence from China," unpublished manuscript, Columbia Business School.

Laurens, Bernard J. and Rodolfo Maino (2007), "China: Strengthening Monetary Policy Implementation," IMF Working Paper 07/14.

Lescaroux, François and Valérie Mignon (2009), "Measuring the Effects of Oil Prices on China's Economy: A Factor-Augmented Vector Autoregressive Approach," Pacific Economic Review 14(3), 410-425.

Nakamura, Emi, Jón Steinsson, and Miao Liu (2014), “Are Chinese Growth and Inflation Too Smooth?” NBER Working Paper 19893.

Qin, Duo, Pilipinas Quising, Xinhua He, and Shigou Liu (2005), "Modeling Monetary Policy Transmission and Policy in China," Journal of Policy Modeling 27, 157-175.

Sargent, Thomas and Christopher Sims (1977), "Business Cycle Modeling without Pretending to have Too Much A Priori Economic Theory," in Sims, C. et al. (eds.), New Methods in Business Cycle Research (Federal Reserve Bank of Minneapolis: Minneapolis).

Stock, James and Mark Watson (1998), "Diffusion Indexes," NBER Working Paper 6702.

Stock, James and Mark Watson (1999), "Forecasting Inflation,” Journal of Monetary Economics 44, 293-335.

Stock, James and Mark Watson (2002), "Macroeconomic Forecasting Using Diffusion Indexes," Journal of Business and Economic Statistics 20, 147-62. 
Stock, James and Mark Watson (2012). "Disentangling the Channels of the 2007-2009 Recession.” Brookings Papers on Economic Activity, Spring, 81-135.

Sun, Lixin, J. L. Ford, and David G. Dickinson (2010), "Bank Loans and the Effects of Monetary Policy in China: VAR/VECM Approach," China Economic Review 21, 65-97.

Wikileaks (2007). http://wikileaks.org/cable/2007/03/07BEIJING1760.html.

Zhang, Wenlang (2009), “China's Monetary Policy: Quantity Versus Price Rules,” Journal of Macroeconomics 31, 473-484. 


\begin{tabular}{|c|c|c|c|}
\hline & Data series & $\begin{array}{l}\text { First } \\
\text { observation }\end{array}$ & $\begin{array}{l}\text { Last } \\
\text { observation }\end{array}$ \\
\hline \multirow[t]{30}{*}{$\begin{array}{l}\text { Broad } \\
\text { Economic } \\
\text { Activity } \\
\text { Factor }\end{array}$} & \# employees: industrial enterprise & $2005 \mathrm{~m} 12$ & $2012 \mathrm{~m} 12$ \\
\hline & Consumer Confidence Index & 1990m1 & 2013m9 \\
\hline & Exports & $1992 \mathrm{~m} 1$ & $2013 \mathrm{~m} 10$ \\
\hline & Trade Balance & $1992 m 1$ & $2013 m 10$ \\
\hline & $\begin{array}{l}\text { Import sitc: MF: Petroleum, Petroleum Pdt } \\
\text { \& Related Material }\end{array}$ & 1994m1 & $2013 m 9$ \\
\hline & Foreign Reserve & $1989 \mathrm{~m} 1$ & $2013 m 9$ \\
\hline & FX Rate: PBOC: Month End: RMB to USD & $1994 m 1$ & $2013 m 10$ \\
\hline & Fixed Asset Investment & $1994 m 1$ & $2013 \mathrm{~m} 10$ \\
\hline & FAI:: New Construction & 1999m8 & $2013 m 10$ \\
\hline & FAl:: Equipment Purchase & $2004 m 1$ & $2013 \mathrm{~m} 10$ \\
\hline & PMI: Non Mfg: Business Activity & $2007 \mathrm{~m} 1$ & $2013 \mathrm{~m} 10$ \\
\hline & Index: Shanghai Stock Exchange: Composite & $1990 \mathrm{~m} 12$ & $2013 \mathrm{~m} 10$ \\
\hline & $\begin{array}{l}\text { Index: Shenzhen Stock Exchange: } \\
\text { Composite }\end{array}$ & $1991 \mathrm{~m} 4$ & $2013 \mathrm{~m} 10$ \\
\hline & Index: Shanghai Shenzhen 300 Index & $2005 \mathrm{~m} 4$ & $2013 \mathrm{~m} 10$ \\
\hline & PE Ratio: Shanghai SE: All Share & $1996 m 8$ & $2013 \mathrm{~m} 10$ \\
\hline & PE Ratio: Shenzhen SE: All Share & 1994m1 & $2013 \mathrm{~m} 10$ \\
\hline & Real Estate Climate Index (RECI) & $2004 \mathrm{~m} 1$ & $2013 m 10$ \\
\hline & Electricity consumption & $2002 m 12$ & $2013 m 9$ \\
\hline & Electricity production & 1996m1 & 2013m9 \\
\hline & Rail freight traffic & $1998 m 8$ & $2013 m 9$ \\
\hline & Real Estate Investment: Residential Building & $1995 \mathrm{~m} 12$ & 2013m9 \\
\hline & Crude steel production & $2001 \mathrm{~m} 1$ & $2013 m 9$ \\
\hline & Trucks sales & $2005 m 1$ & $2013 m 9$ \\
\hline & Purchasing Managers' Index & $2005 m 1$ & $2013 m 9$ \\
\hline & PMI: Mfg: New Export Order & $2005 \mathrm{~m} 1$ & 2013m9 \\
\hline & Consumer Expectation Index & 1990m1 & $2013 m 9$ \\
\hline & Floor Space Started: Commodity Building & $1995 \mathrm{~m} 12$ & 2013m9 \\
\hline & Retail Sales of Consumer Goods & 1990m1 & $2013 m 9$ \\
\hline & Industrial production & 1995m1 & 2013m9 \\
\hline & Gas consumption index & $2003 m 1$ & $2013 \mathrm{~m} 3$ \\
\hline $\begin{array}{l}\text { Narrow } \\
\text { Economic }\end{array}$ & Exports & $1992 \mathrm{~m} 1$ & $2013 m 10$ \\
\hline
\end{tabular}




\begin{tabular}{|l|l|l|l|}
\hline $\begin{array}{l}\text { Activity } \\
\text { Factor }\end{array}$ & & & \\
\hline & Electricity production & $1996 \mathrm{~m} 1$ & $2013 \mathrm{~m} 9$ \\
\hline & Floor Space Started: Commodity Building & $1995 \mathrm{~m} 12$ & $2013 \mathrm{~m} 9$ \\
\hline & & & \\
\hline $\begin{array}{l}\text { Price } \\
\text { Factor }\end{array}$ & Consumer Price Index & $1995 \mathrm{~m} 1$ & $2013 \mathrm{~m} 10$ \\
\hline & CPI Core (excl. Food \& Energy) & & \\
\hline & CPI Food & $2006 \mathrm{~m} 1$ & $2013 \mathrm{~m} 10$ \\
\hline & Consumer Price Index: 36 City & $1995 \mathrm{~m} 1$ & $2013 \mathrm{~m} 10$ \\
\hline & & $2002 \mathrm{~m} 1$ & $2013 \mathrm{~m} 9$ \\
\hline $\begin{array}{l}\text { Policy } \\
\text { Variables }\end{array}$ & Govt Expenditure & & \\
\hline & Money Supply M2 & $1995 \mathrm{~m} 1$ & $2013 \mathrm{~m} 9$ \\
\hline & Required Reserve Ratio & $1997 \mathrm{~m} 1$ & $2013 \mathrm{~m} 10$ \\
\hline & $\begin{array}{l}\text { Central Bank Benchmark Interest Rate: } \\
\text { Loans less than 20 days }\end{array}$ & $1985 \mathrm{~m} 1$ & $2013 \mathrm{~m} 10$ \\
\hline & Loans & $1993 \mathrm{~m} 5$ & $2013 \mathrm{~m} 10$ \\
\hline & & $1997 \mathrm{~m} 1$ & $2013 \mathrm{~m} 9$ \\
\hline & US Industrial production & $1985 \mathrm{~m} 1$ & $2013 \mathrm{~m} 11$ \\
\hline & Commodity prices & $1991 \mathrm{~m} 1$ & $2013 \mathrm{~m} 12$ \\
\hline
\end{tabular}

Note: U.S. Industrial Production and Commodity Prices were downloaded from Haver Analytics. All other variables were downloaded from the CEIC Asia database. 


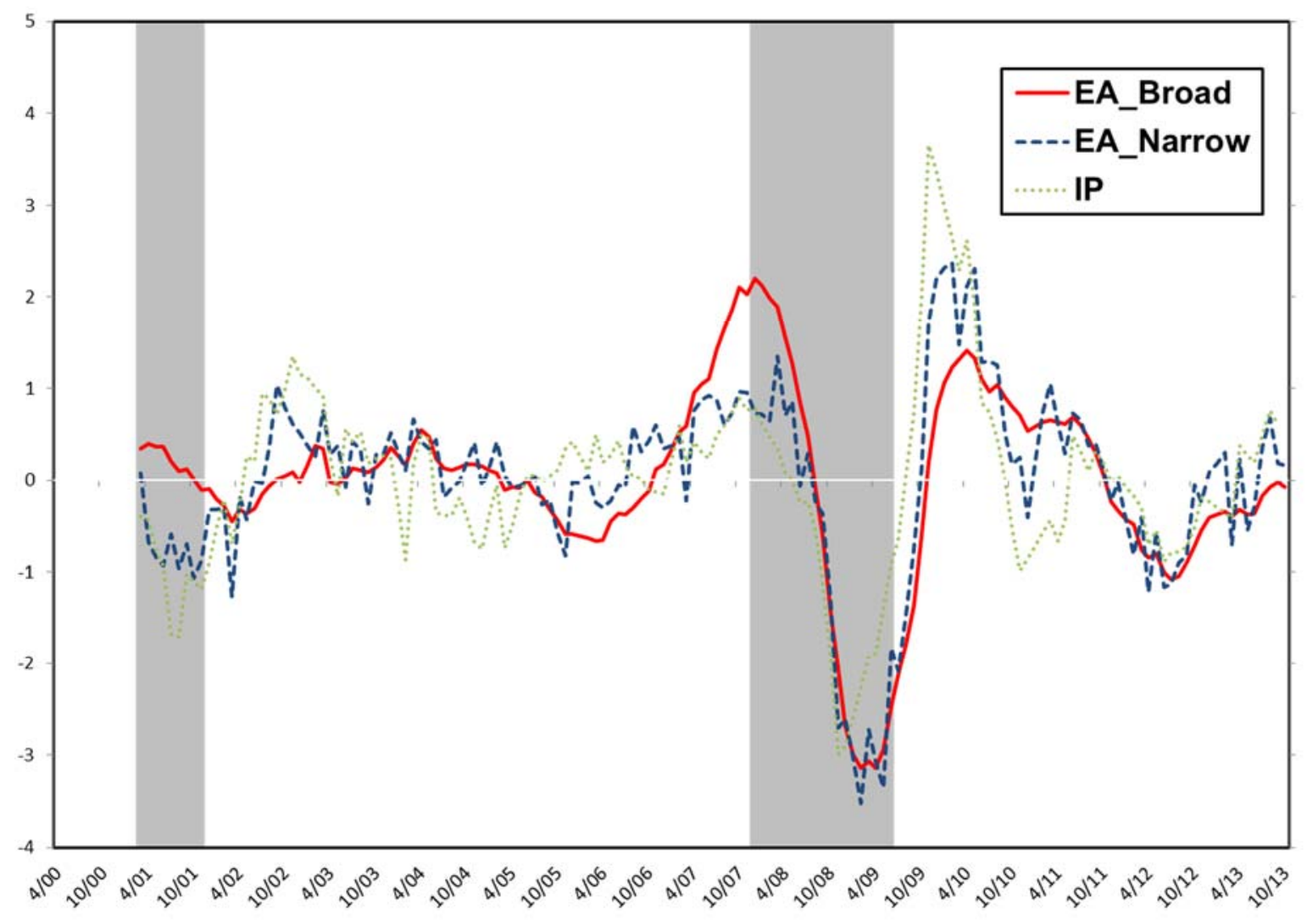

Figure 1a: Broad and Narrow Economic Activity Factors. The figure shows the economic activity factors extracted from broad and narrow sets of economic indicators. The solid (red) line depicts the broad activity factor, dashed (blue) line the narrow activity factor, and dotted (green) line Chinese industrial production for comparison. For all series, we took the twelve-month moving average and then normalized to mean zero and unit variance. 


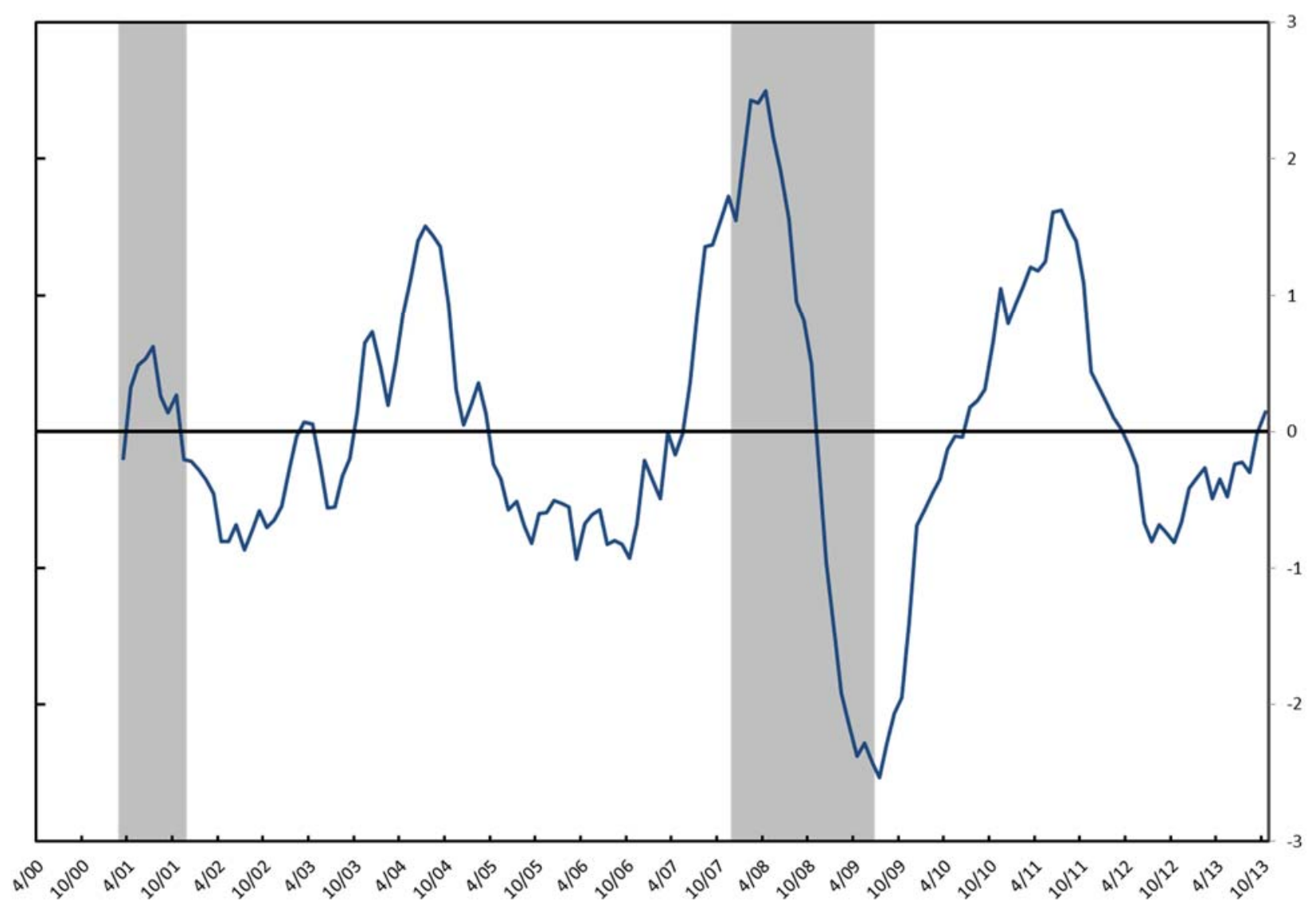

Figure 1b: Inflation Factor. The figure shows twelve-month moving average of the inflation factor, normalized to mean zero and unit variance. 

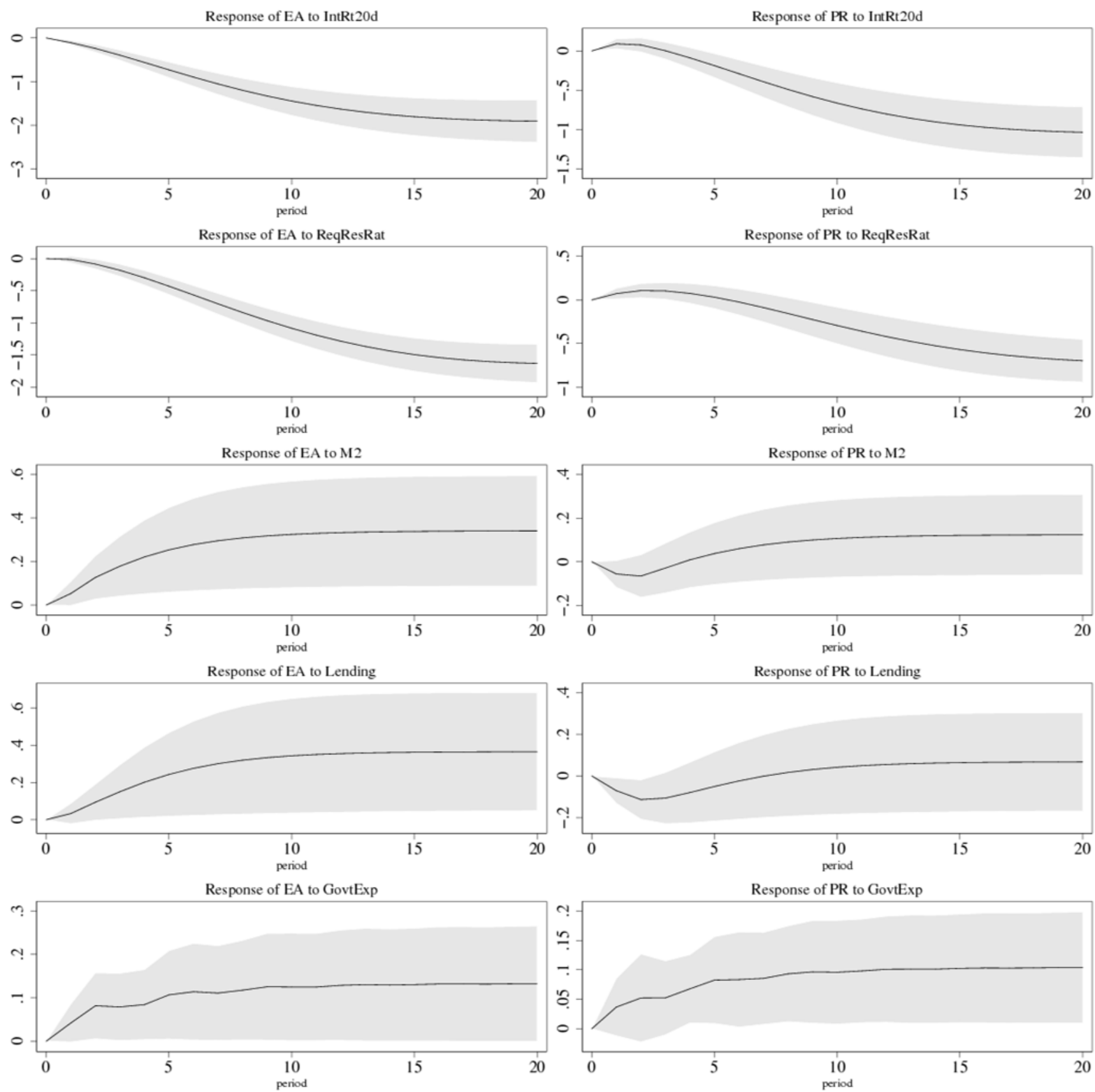

Figure 2: Impulse Responses from Three-Variable VARs (with Broad EA Factor). Note: Three-Variable VARs (broad economic activity factor, inflation factor, policy variable). Each row corresponds to a separate three-variable VAR, with the broad economic activity factor (EA), inflation factor (PR), and the policy variable shown. The left column shows the impulse response function of the economic activity factor, and the right column shows the impulse response of the inflation factor, to a policy innovation. Impulse responses are in logarithmic percent and are cumulative responses to a one-standard-deviation innovation. Shaded areas indicate bootstrapped one-standard-error bands around the point estimates. Periods are months. 

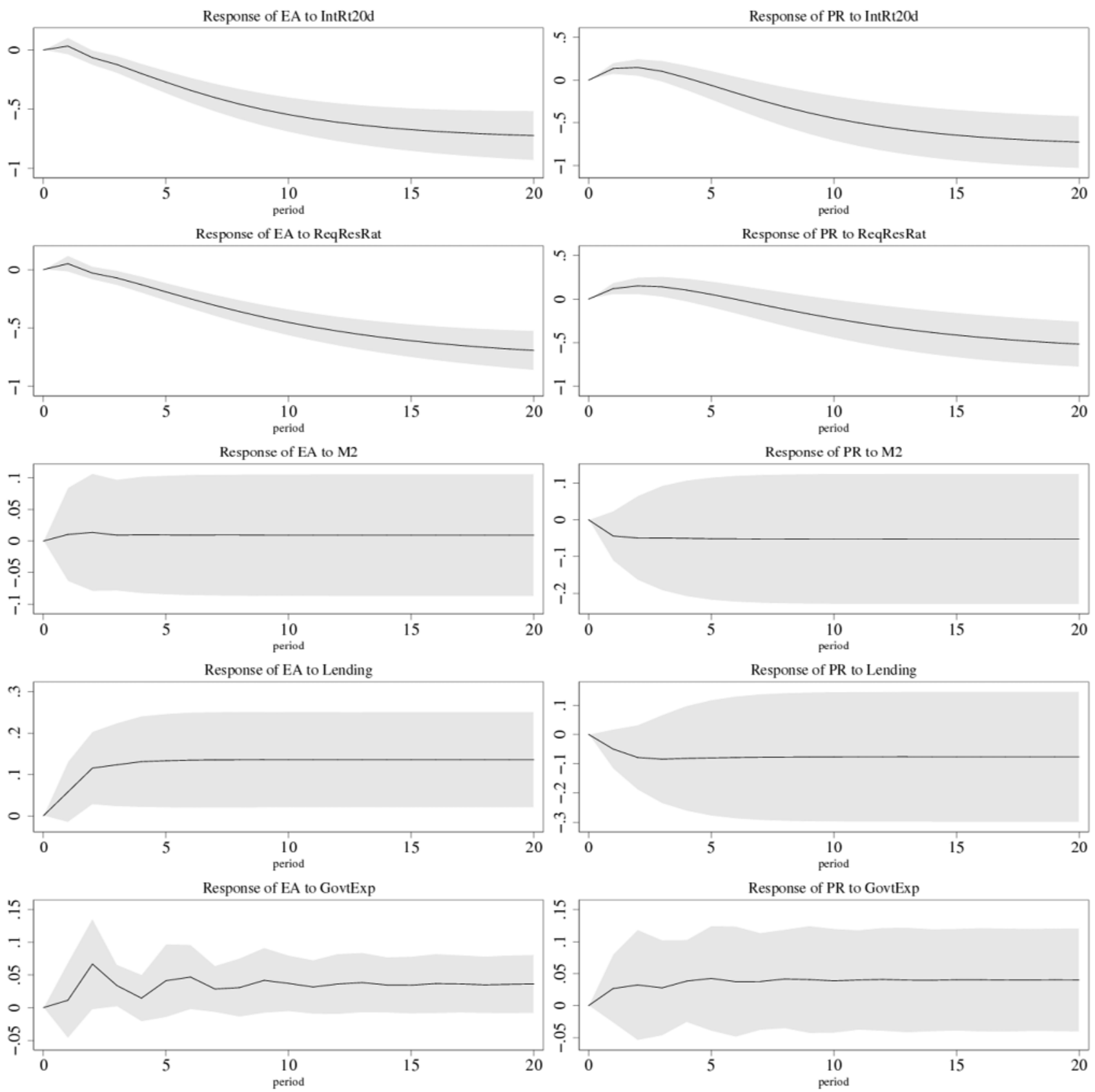

Figure 3: Impulse Responses from Three-Variable VARs (with Narrow EA Factor). ThreeVariable VARs (narrow economic activity factor, inflation factor, policy variable). Each row corresponds to a separate three-variable VAR, with the narrow economic activity factor (EA), inflation factor (PR), and the policy variable shown. The left column shows the impulse response function of the economic activity factor, and the right column shows the impulse response of the inflation factor, to a policy innovation. Impulse responses are in logarithmic percent and are cumulative responses to a one-standard-deviation innovation. Shaded areas indicate bootstrapped one-standard-error bands around the point estimates. Periods are months. 

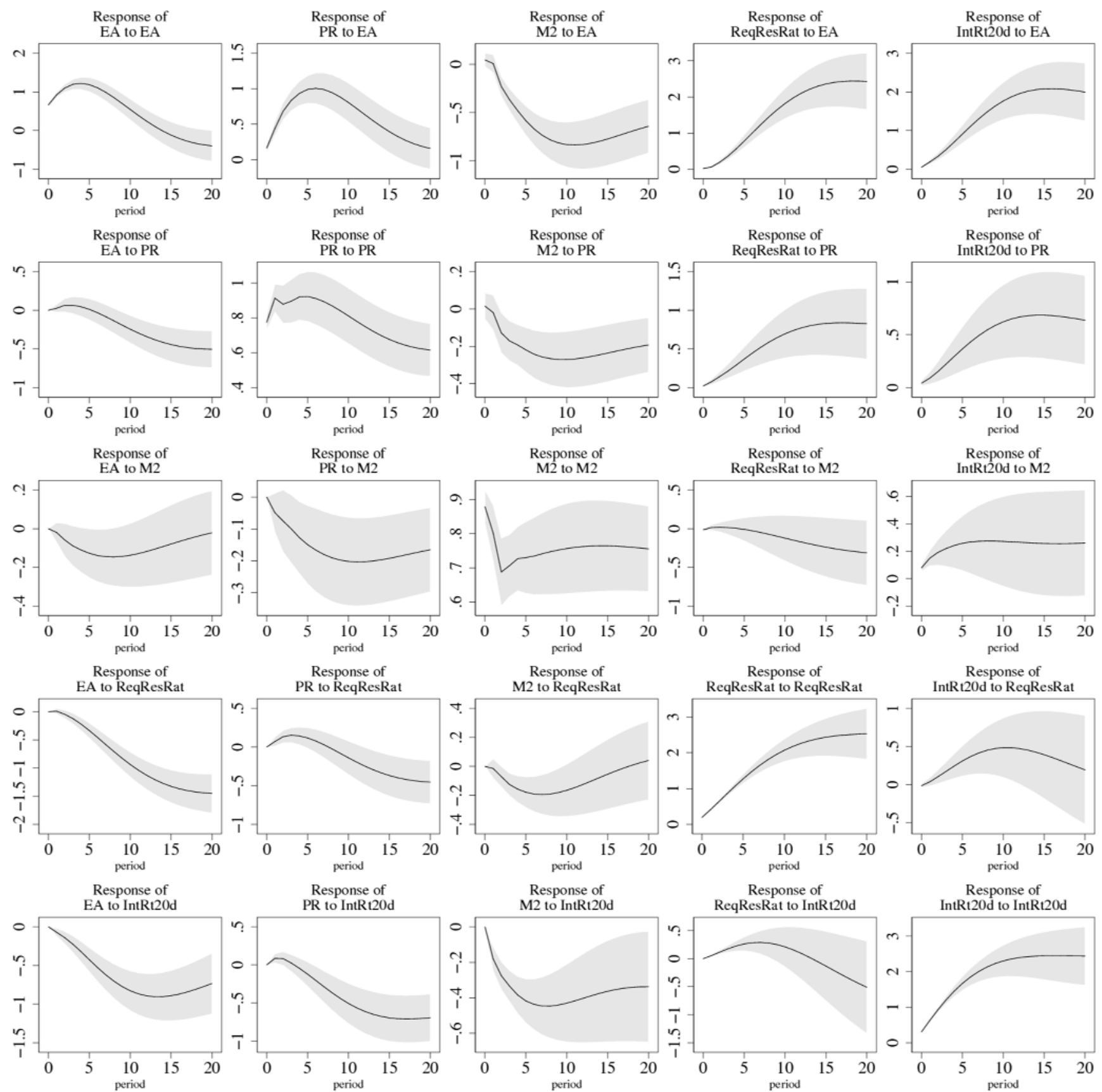

Figure 4: Five-Variable FAVAR System (with M2 and Reserves). Five-variable VAR (broad economic activity factor, inflation factor, M2, required reserves, interest rate). Identification is recursive, in the order listed. Graphs show cumulative responses to a one-standard-deviation innovation. Impulse responses for EA, PR, and M2 are in logarithmic percent, ReqResRat and IntRt20d are in percentage points. Shaded areas indicate bootstrapped one-standard-error bands. Periods are months. 

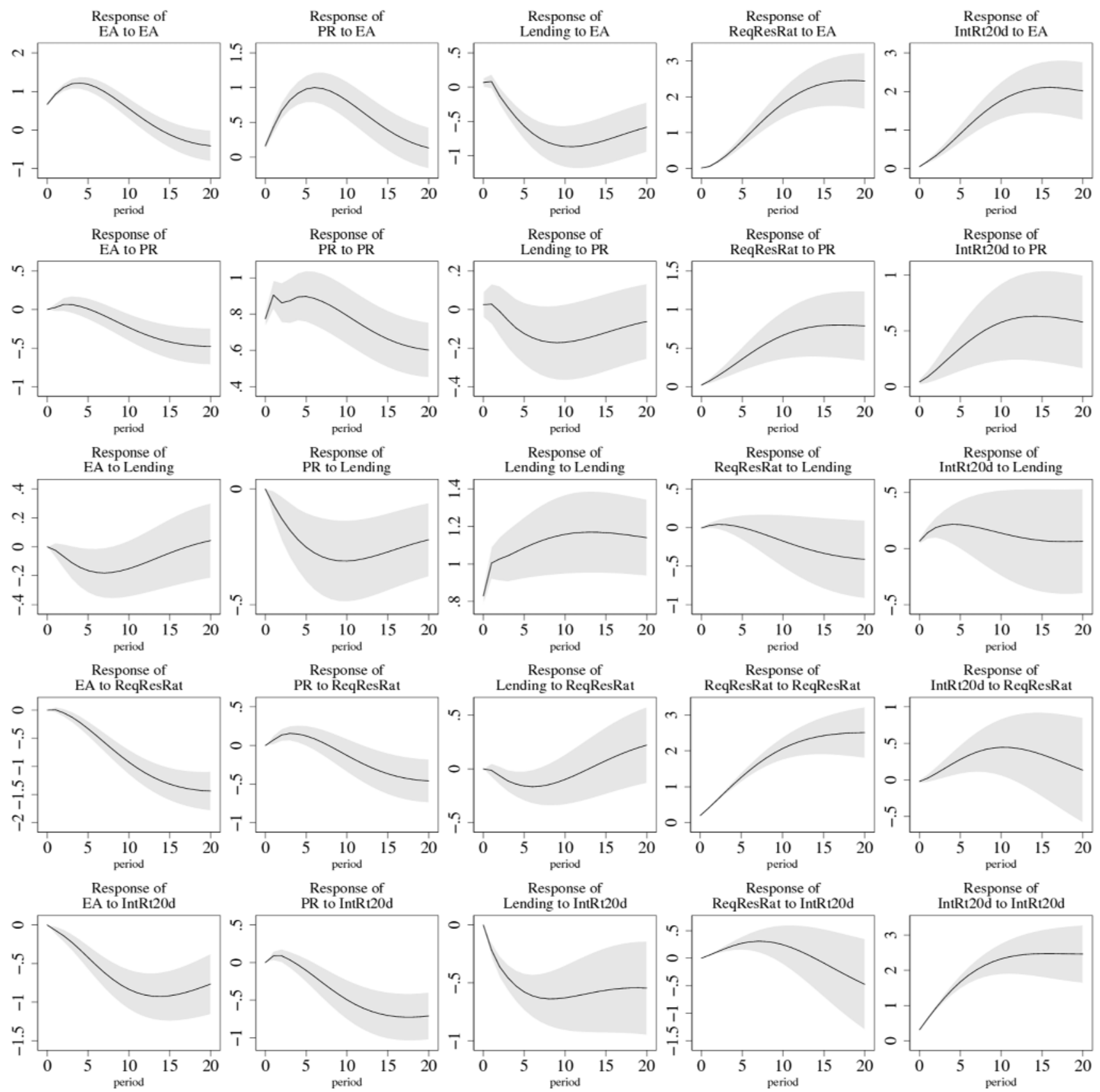

Figure 5: Five-Variable FAVAR System (with Bank Lending and Reserves). Five-variable VAR (broad economic activity factor, inflation factor, bank lending, required reserves, interest rate). Identification is recursive, in the order listed. Graphs show cumulative responses to a onestandard-deviation innovation. Impulse responses for EA, PR and Lending are in logarithmic percent, ReqResRat and IntRt20d are in percentage points. Shaded areas indicate bootstrapped one-standard-error bands. Periods are months. 

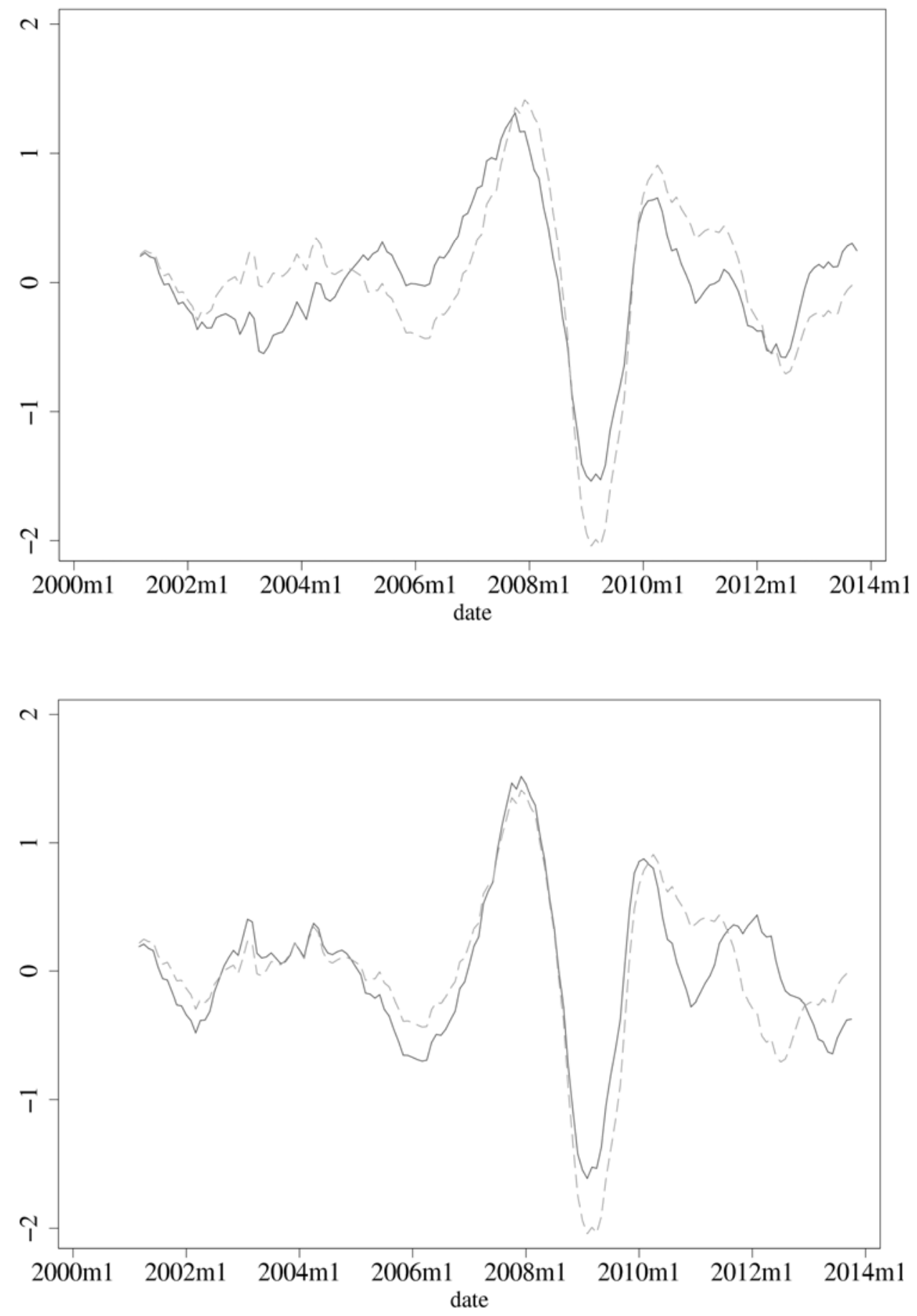

Figure 6a and Figure 6b: Contribution of Interest Rate (top) and Reserve Requirements (bottom) to Economic Activity. Contribution of reserve requirements and interest rates to broad economic activity factor over our sample. The dashed (red) line in each panel depicts the estimated economic activity factor. The solid (blue) line depicts the counterfactual values from a three-variable VAR, setting the innovations to the short-term interest rate or reserve requirements to zero. 

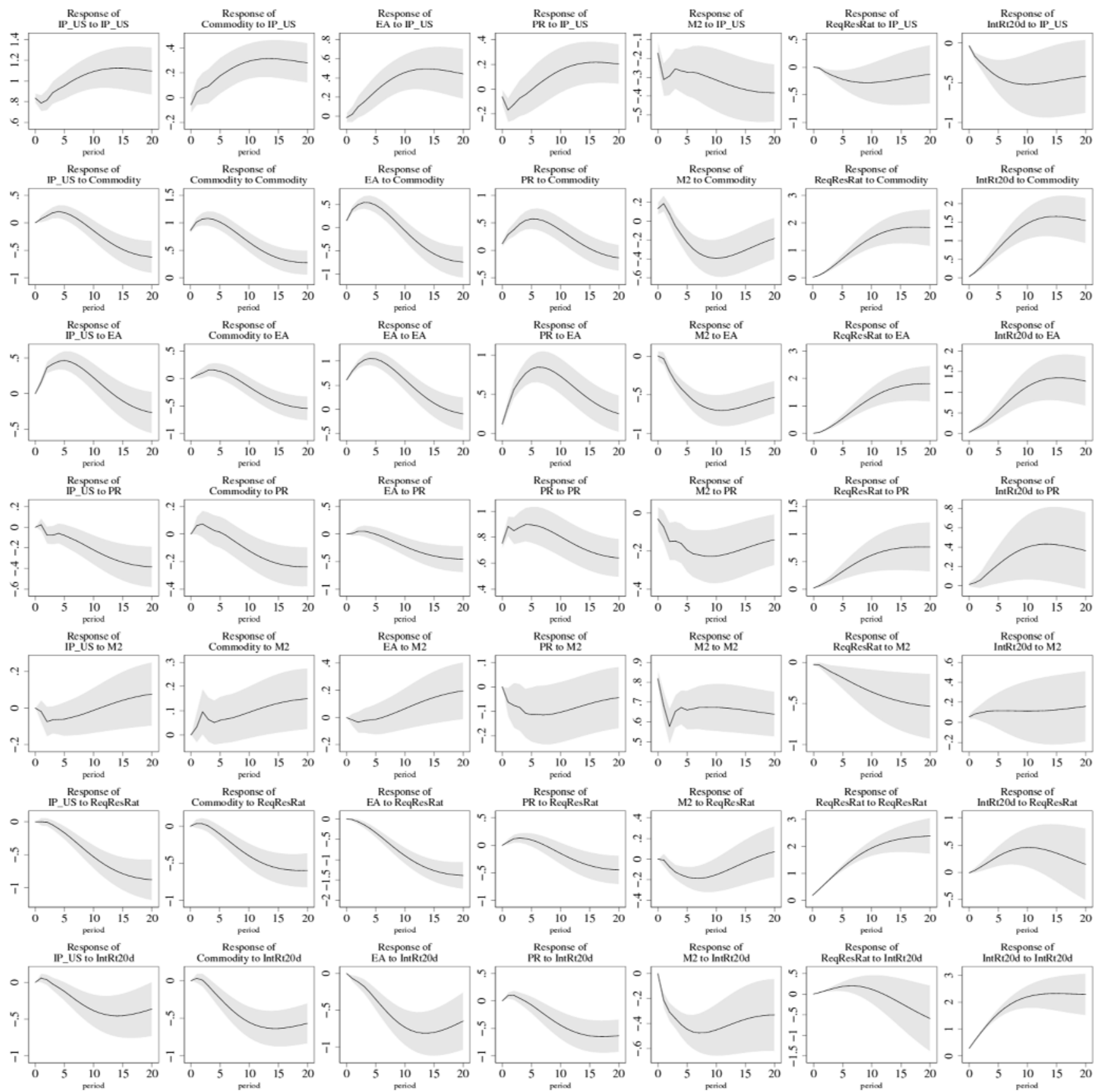

Figure 7: Seven-Variable FAVAR (with US Industrial Production and Commodity Prices). Seven-variable VAR (U.S. industrial production, commodity prices, broad economic activity factor, inflation factor, M2, required reserves, interest rate). Identification is recursive, in the order listed. Graphs show cumulative responses to a one-standard-deviation innovation. Impulse responses for IP_US, Commodity, EA, PR, and M2 are in logarithmic percent, ReqResRat and IntRt20d are in percentage points. Shaded areas indicate bootstrapped onestandard-error bands. Periods are months. 


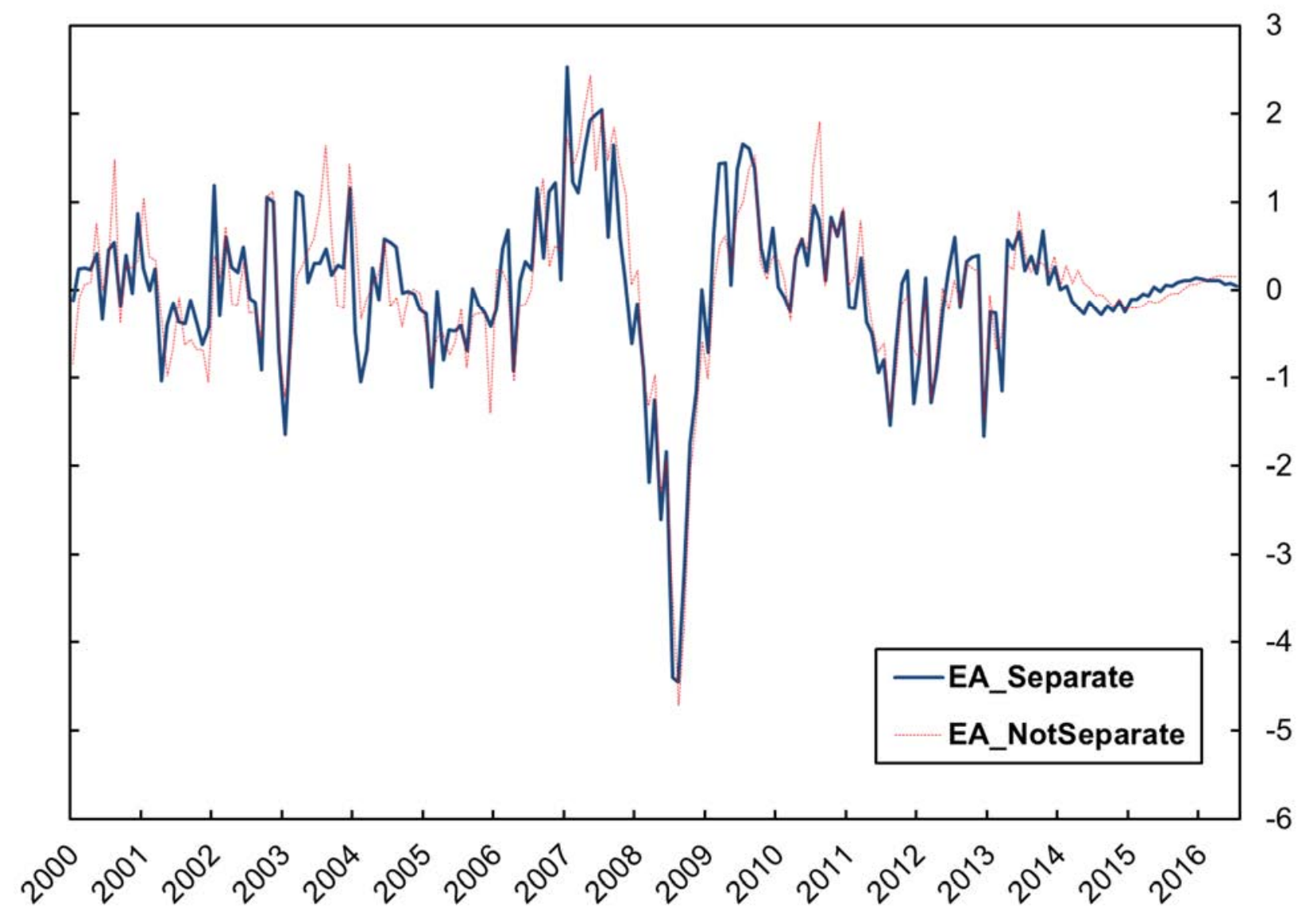

Figure 8a: Output and Inflation Factors Estimated using All Data. The figure shows two economic activity factors. The solid line represents our baseline economic activity factor. The dashed (red) line represents the first latent factor where economic activity and price input series are not separated into two groups. 


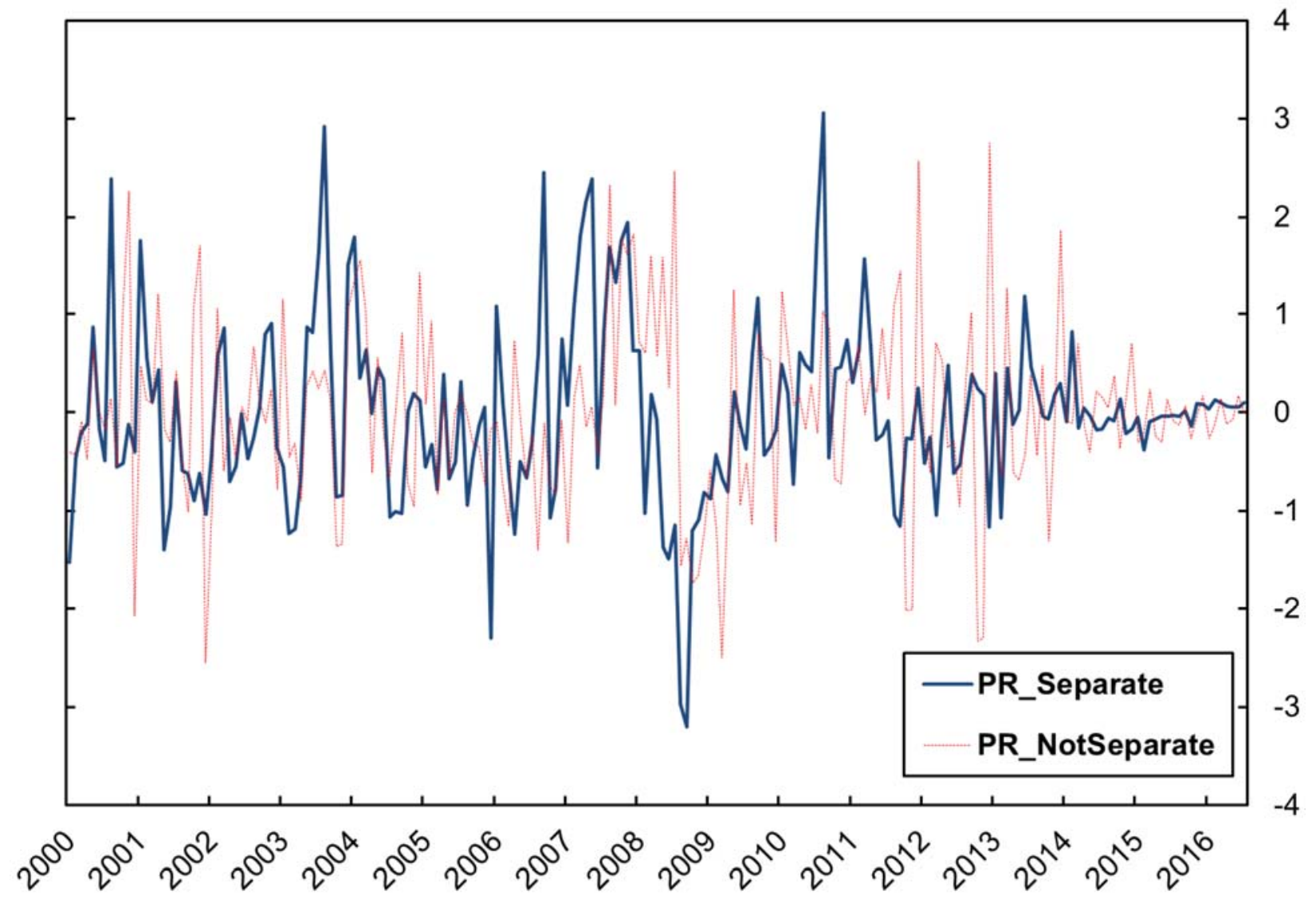

Figure 8b. The figure shows two inflation factors. The solid line represents our baseline inflation factor. The dashed (red) line represents the second latent factor where economic activity and price input series are not separated into two groups. 

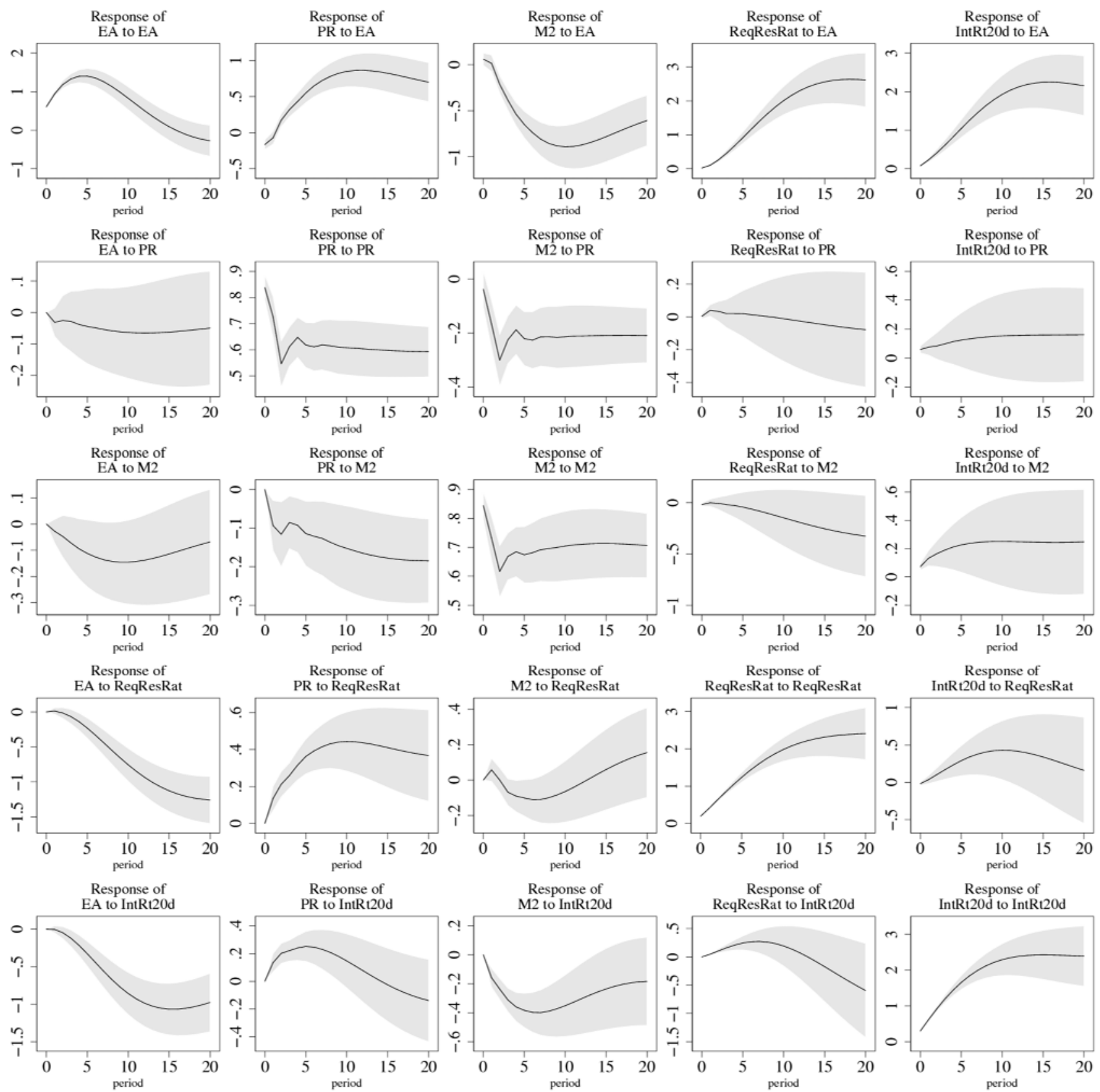

Figure A1. Five-Variable System with Factors estimated with all observable non-policy variables (Factor 1, Factor 2, M2, Required Reserves, Interest Rate). Note that in these graphs, "EA" refers to Factor 1, and "PR" refers to Factor 2. Graphs show cumulative responses to a one-standard-deviation innovation. Impulse responses for EA, PR, and M2 are in logarithmic percent, ReqResRat and IntRt20d are in percentage points. Shaded areas indicate bootstrapped one-standard-error bands. Periods are months. 